\title{
AN ANALYTICAL EVALUATION OF HISTORIC GLAZED TILES FROM MAKLI AND LAHORE, PAKISTAN
}

\author{
Maninder Singh Gill1 ${ }^{1}$ Thilo Rehren ${ }^{2}$
}

${ }^{1}$ UCL Qatar, Hamad bin Khalifa University, Doha, Qatar

${ }^{2}$ UCL Institute of Archaeology, London, UK; College of Humanities and Social Sciences, HBKU, Qatar

\section{Abstract}

The composition and production of early modern glazed tiles in Pakistan are poorly understood. Here, 38 glazed tile samples sourced from various monuments at Makli Hill and Lahore Fort in Pakistan, dating mainly from the sixteenth and seventeenth centuries $\mathrm{CE}$, were investigated with scanning electron microscopy and energy dispersive $X$-ray spectrometry for a comprehensive technological study to understand the methods used in their production. The analyses were supplemented by laser ablation-inductively coupled plasma-mass spectrometry to more fully characterise the raw materials used for the glazes. The Makli tile bodies are composed of clay-based ceramic whereas those from Lahore are stonepaste. Both are coated with soda-lime-silica glazes made using plant ash. Cobalt, copper, lead-tin yellow and lead-tin orange are identified as the glaze colorants. White glazes do not have an added opacifier or colorant, but are white due to the presence of an underlying layer of silica particles. Technological variations between the Makli and Lahore tiles are highlighted in the discussions, the former found to resemble traditional kashi ware of Sindh-Multan in their make-up, while the latter matches Mughal tile-work that prevailed for a while locally in the seventeenth century.

\section{Keywords}

GLAZED TILES, KASHI, PAKISTAN, MAKLI, LAHORE, TECHNOLOGY, SEM-EDS, LA-ICP-MS

\section{INTRODUCTION}

The use of glazed revetments to decorate buildings goes back to the Late Bronze Age, where tiles of Egyptian faience were embellishing the temples and palaces of the pharaohs (Friedman 1998, Delange 2015), continuing with clay-based ceramic tiles or bricks such as those found on the famous Iron Age Ishtar Gate and Processional Way, originally from Babylon in Iraq (Matson 1986, Paynter 2008). Later, in the medieval period, the use of glazed tiles reached a new height in Islamic architecture (Porter 1995), both in Turkey (Carswell 1998) and in Central Asia from Iran to Uzbekistan (Grazhdankina et al. 2006). From here, the tradition spread south into India and Pakistan, in the wake of the establishment of Islamic dynasties in the Indian Subcontinent.

In Pakistan, the art or craft of tiling is virtually synonymous with the term kashi, which refers to the manufacture of a particular variety of fine glazed ware, mainly tiles for the ornamentation of buildings. Although the kashi traditions are specific only to a geographic region covering the arid lands of the lower Punjab (Multan in central Pakistan being the main centre here) and Sindh (Hala, Thatta and Nasarpur in SE Pakistan being known centres of production here) provinces, the term is often loosely, and perhaps erroneously, applied to other historic tiles or tile-work in Pakistan as well, notably to a different and distinct stylistic form found in Lahore city and its environs in the northern part of Punjab (Figure 1). Between the two, the kashi or Sindh-Multan type of tile-work, characterized by a dominant blue-and-white colour scheme, is the older and longer-established of the two forms, carrying on 
apparently as an unbroken tradition from the 14th century through to the present date (Degeorge and Porter 2002, 244-253, Akhund and Askari 2011, 65-70, UNESCO 2015). The Lahore variety of tile-work, marked by the extensive use of a multi-coloured tile-mosaic, appears much later, in the early 17th century, and flourishes for a considerably shorter duration, practically ceasing by the third quarter of the same century (Vogel 1920, 6-15, Rehmani 1997-98).

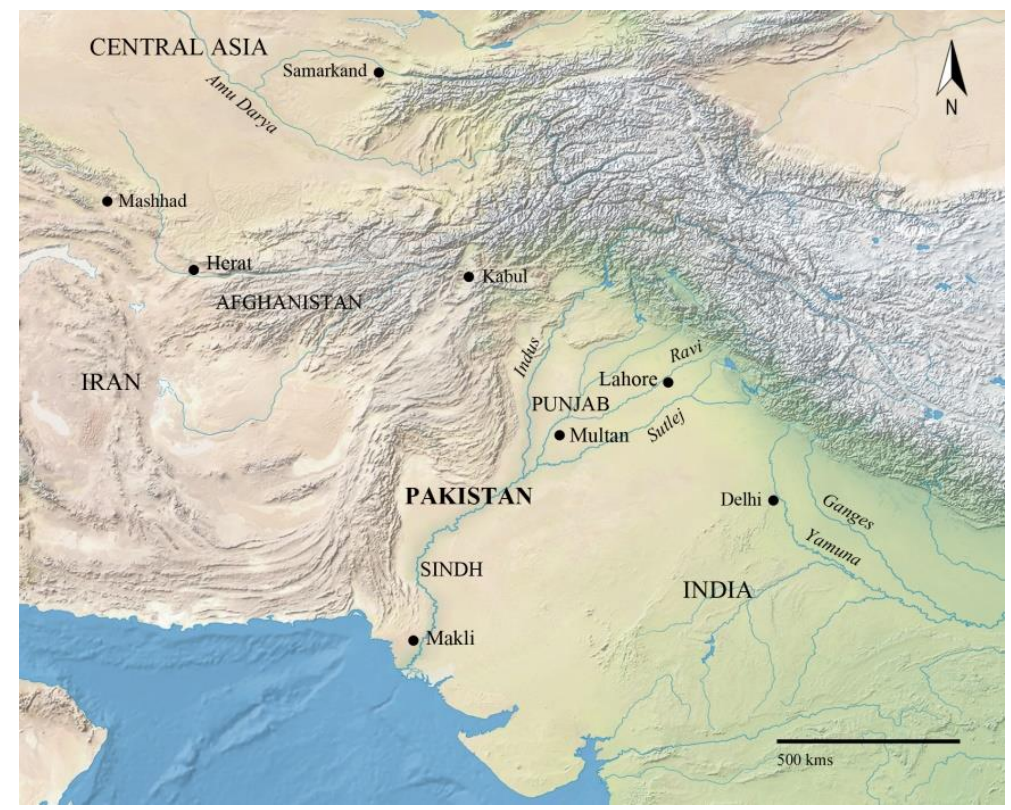

Figure 1. Map of the region showing the location of the sites.

While numerous buildings adorned with these two broad varieties of tile-work are known to exist, little is known of the original technologies that went into their making. We are aware of only one published technical study on the Lahore tiles (Gulzar et al. 2013), and none on the kashi Sindh-Multan type despite its cultural longevity and importance. Most available information on these tiles is from various surveys, compilations, and ethnographic studies (Birdwood 1884, Furnival 1904, Cousens 1906, Cousens 1929, Rye and Evans 1976, Khan 1990), which although detailed for their own purposes, are insufficient for reconstructing the production processes originally involved. This paucity of data has led to an incomplete understanding of the Sindh-Multan and Lahore tiling traditions, necessitating a detailed study to identify the materials and characteristics associated with each.

For this, 38 tile fragments made available through the UNESCO World Heritage Centre (Paris) in collaboration with the governments of Sindh and Punjab (Pakistan) were analysed at the Archaeological Materials Science Laboratories of UCL Qatar (see Supporting Online Material A). Twenty nine of these samples are from various historic buildings at the World Heritage Site (WHS) of Makli Hill. The site, located near Thatta in Sindh, comprises a vast cemetery of numerous medieval/early-modern tombs and graves, the larger and more impressive of which represent the architectural (and embellishing) traditions of the various dynasties that ruled Sindh from the 14th to 18th centuries, from the Samma (mid-14th to early-16th centuries), Arghun (early- to mid-16th century) and Tarkhan (mid- to late-16th century), to the Mughal (early-17th to early-18th century). Most of the buildings from where the samples have been sourced are ascribed to the 16th and 17th centuries. One sample (MA-20) is from a building dating to the 14th century. Sampling details provided together with the samples indicate that the majority of the tiles were originally installed on the exteriors of the buildings, as detailed in SOM A. 
The other nine samples are from the 'Picture Wall' of Lahore Fort, a monumental Mughal citadel that forms part of the WHS listed Fort and Shalamar Gardens ensemble at Lahore city. The fort is considered to have been given its current basic form by the third Mughal emperor Akbar (1556-1605), but the tile-work that it has is attributed to his descendants and successors, Jahangir (1605-1627) and Shah Jahan (1628-1657) (Vogel 1920, 50-55). The tiles from the Makli buildings are representative of the kashi tile-work of Sindh, while those from Lahore Fort are on the lines typically associated with Lahore city.

\section{METHODOLOGY}

The samples were first documented and examined macroscopically using a hand lens. Representative sections of each were then cut through the body and glaze, and mounted in resin blocks. One sample from Lahore Fort, LF-07, which first appeared to be a single green-and-yellow polychrome glazed tile, was found to actually comprise two distinct tiles, one of which (yellow-glazed) had been inlaid in the other (green-glazed). These were accordingly treated as two separate tiles for the purpose of analysis, and numbered as LF-07a and LF-07b respectively. Sample MA-28 from Makli was also found to consist of several individual tiles of two distinct colours (turquoise and dark-blue) that had been arranged in the form of a polychromatic composition. One representative sample of each of these colours was taken for analysis, and numbered as MA-28a (turquoise) and MA-28b (dark-blue).

All mounted samples were ground and polished using standard procedures to expose clean crosssections for detailed microscopic examination. Optical microscopy was undertaken using a Leica DM2500P microscope with reflected light. The polished blocks were then carbon coated to make them conductive and examined using a JEOL JSM6610LV scanning electron microscope (SEM). Observations were made in backscattered electron (BSE) mode, and chemical analysis was conducted using an attached Oxford Instruments X-Max energy dispersive spectrometer (EDS), operating at an accelerating potential of $20 \mathrm{kV}$, count time 60 seconds, and average dead-time of $35-40 \%$. Quantitative analyses report the average of 5 area analyses spread across the body or glaze layer of each tile as applicable. Individual particles or phases in the bodies and glazes were subject to spot or small-area analysis at the same settings. Each area analysis covered an expanse of c. $1.25 \times 1 \mathrm{~mm}$ on the sample surface in the case of the bodies, and c. $150 \times 110 \mu \mathrm{m}$ in the case of the glaze layers. Areas scanned through small-area analysis were typically of the order $50 \times 50 \mu \mathrm{m}$ or less.

High analytical totals, mostly $100 \pm 1 \mathrm{wt} \%$, were achieved in the bulk analyses of the glaze layers, the glazes individually being homogeneous and remarkably free of corrosion. The tile bodies, while also being consistent across in their composition individually, returned lower totals, in the range of 60-75 $w t \%$, on account of their inherent porosity. Results of the chemical analyses for the bodies and glaze layers are reported as oxides by stoichiometry, normalized to $100 \%$, while the trace element data obtained through LA-ICP-MS is given in element ppm. Reduced compositions of the glaze layers, where given, have been calculated by subtracting the colorants from the analytical results and normalizing the totals of the base glass forming oxides to $100 \%$. The lower detection limits of the EDS and LA-ICPMS systems have been considered to be $0.3 \mathrm{wt} \%$ and $10 \mathrm{ppm}$ respectively.

A limited number of the Makli and Lahore glazes were further analysed through Laser AblationInductively Coupled Plasma-Mass Spectrometry (LA-ICP-MS). The aim of this was to get a full trace element characterization to facilitate discussion of raw materials and differences between and within glazes from the two sites. The analyses were carried out at the Institut de Recherche sur les 
Archéomatériaux (IRAMAT UMR-5060 CEB), CNRS Orléans. The LA-ICP-MS system employed consisted of a Thermo Fisher Scientific ELEMENT XR ICP-MS coupled to a Resonetic M50E $193 \mathrm{~nm}$ ArF excimer laser source. The spot size of the laser beam varied over 30-100 $\mu \mathrm{m}$, while the frequency was set to 7 $\mathrm{Hz}$ (Gratuze 2013). Precision and accuracy of the SEM-EDS and LA-ICP-MS systems were checked against Corning reference material (Corning $A$ and $C$ glass standards).

\section{MACROSCOPIC EXAMINATION}

The samples from the two sites differ from each other even macroscopically. The Makli tile samples (MA series) have characteristic terracotta-red coloured bodies, which together with their general bulky size (several being as large as $20 \mathrm{~cm}$ across) and opaque glazes resemble glazed bricks (Figure 2). They are, however, distinct from bricks having superior, highly refined body matrices with very few visible voids or inclusions. The distinctiveness of these tiles from bricks is further illustrated by the tapering or bevelling of their sides, indicating that they were purposefully constructed to be decorative wall-revetments rather than for masonry work.

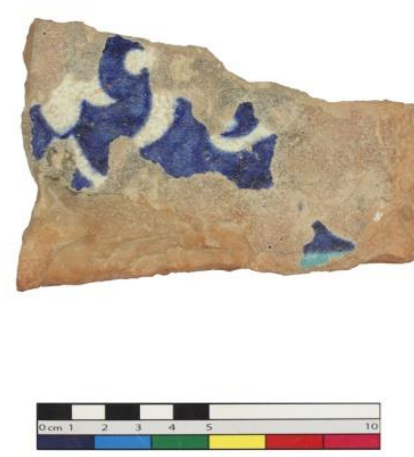

Figure 2. A polychrome blue-and-white glazed tile (MA-11) from a monument at Makli Hill. Note the reddish coloured underlying body where the glaze is missing.
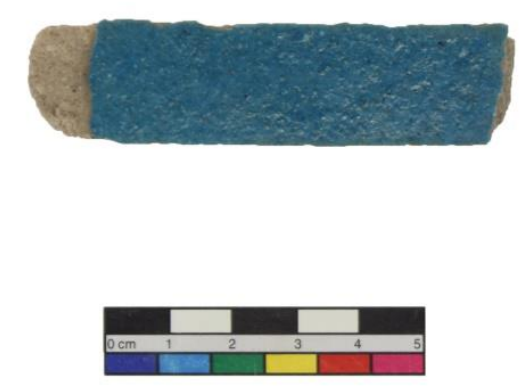

Figure 3. A monochrome turquoise coloured glazed tile (LF-05) from Lahore Fort. All the Lahore Fort tiles have glazes of one colour only.

Both monochrome and polychrome glazes are found among the MA samples, with individual glaze layers being generally around half a millimetre or so in thickness. The colour scheme is restricted to shades of turquoise, dark-blue, and white. No outlining of patterns or delineating line is found between adjacent colours on the polychrome glazes. In spite of this no major flowing or bleeding of colours is noticed.

In contrast, the bodies of the Lahore Fort samples (LF series) are off-white with the hint of a reddish tinge (Figure 3). These bodies are visibly porous, being made up of small particles or grains that have been cemented or fused together. Some variation in the body fabrics, in terms of the size/texture of the grains, is apparent. In thickness, the bodies are however generally uniform, averaging about one centimetre and a half or so. The one exception is LF-08, the body of which is clearly less than a centimetre thick. These tiles are on the whole considerably smaller than those from Makli in their overall size, the largest being around $7 \mathrm{~cm}$ across.

All the LF samples are monochrome, having opaque glazes of one colour only. The range of glaze colours found includes turquoise, dark-blue, white, yellow, orange, and green, with some tonal variations among samples of the same glaze colour. The glaze thicknesses are generally up to half a 
millimetre or so, with the exception of LF-04 and LF-06; their glaze layers are substantially thinner than the others, appearing more like a thin coloured slip.

\section{ANALYTICAL RESULTS}

140

\subsection{Electron microscopy}

\section{Microstructure and tile bodies}

Most terracotta Makli bodies are essentially composed of fine clay-silt minerals that are closely packed together (Figure 4). The infrequent presence of coarser inclusions suggests that little temper, if at all, was added. Only the bodies of samples from the Tomb of Sultan Ibrahim (MA-01 to MA-04) and Unknown Enclosure-1 (MA-10 and MA-11) are somewhat different, having significant numbers of mineral (mainly silica) particles of a medium-coarse size (250-300 microns) distributed uniformly across their matrices. A typical body composition for the Makli samples is: $\mathrm{SiO}_{2}-58.8 \%$; $\mathrm{Na}_{2} \mathrm{O}-1.8 \%$; CaO-8.3\%; $\mathrm{K}_{2} \mathrm{O}-3.2 \%$; $\mathrm{MgO}-3.5 \% ; \mathrm{Al}_{2} \mathrm{O}_{3}-16.9 \%$; $\mathrm{FeO}-6.8 \%$; and $\mathrm{TiO}_{2}-0.8 \%$, indicating that the clay or clays employed for their making are calcareous, feldspathic and ferruginous.

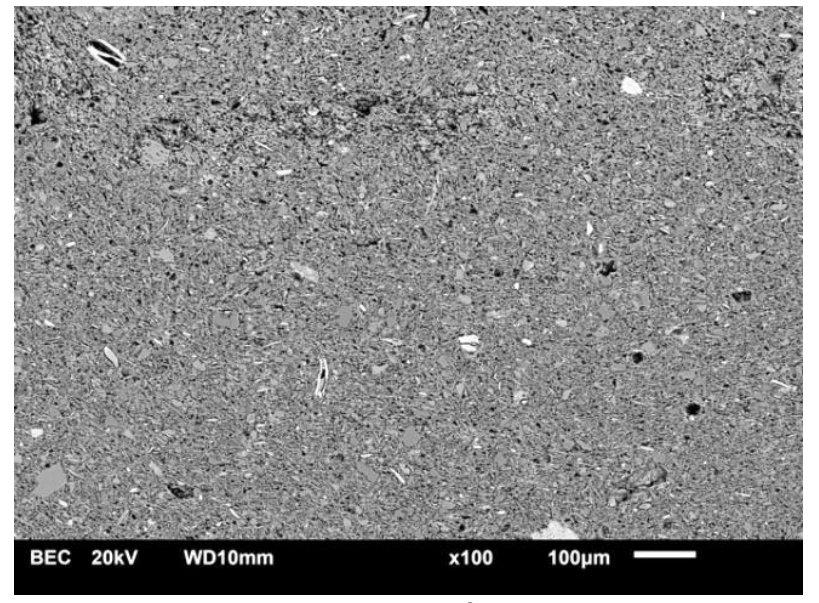

Figure 4. SEM photomicrograph of a typical Makli tile body (MA-09) showing it to be made up mainly of only fine clay-silt minerals.

A slip is found employed in almost all the Makli samples, as a separate layer of fine silica particles at the body-glaze interface (Figure 5). The slip is usually around 200-250 microns in thickness, although in some cases (as in MA-21, MA-24, and MA-25) it may be indistinct or no more than a sprinkling of particles on the body. The glaze layers largely match the slips in thickness, being mostly 250-300 microns thick, although in some instances (as in MA-13 and MA-18) they are noticeably thinner, while in few others (as in MA-21, MA-24, and MA-25) they are up to 500 microns or so thick. A visible sloping of the glaze layers towards the edges that is seen in many of the samples suggests that the tiles were prepared with the intention of being glazed and finished as individual pieces, and were not attained by first producing larger sized tiles that were then cut into smaller pieces (Figure 6). This is corroborated through the macroscopic detection of 'overflow' or 'run-down' patches of the glaze on to the sides of some of the tiles, indicating that the finished fired product was of the same shape/size as that originally covered with the raw glaze.

The Lahore bodies on the other hand are all stonepaste, with highly porous matrices made up almost entirely of silica particles or grains (Figure 7). The silica particles generally fall into two size categories, 
a finer group of 25-100 microns, while the rest are coarser, ranging over 300-500 microns. Although the two size groups are more or less equitably distributed in all the samples, LF-01, LF-04, LF-07a, and LF-08 clearly have enhanced numbers of large coarse grains (c. 500 microns) dispersed in their matrices. Variations are also determined in the textural character of the silica particles in individual samples, and in the employment of slips. In most samples the silica grains appear rounded or semirounded in shape, but this is less apparent in LF-02, LF-03, and LF-08, where appreciable numbers of angular particles can be found as well. A slip layer of fine silica particles is clearly discernible only in samples LF-04, LF-05, and LF-06, where it is around 500-600 microns thick (Figure 8). In others, the presence of a slip may be correlated with the existence of an interaction zone of silica particles that lie submerged in the glaze layers, but this cannot be stated so confidently for LF-03, LF-07a, LF-07b, and LF-08, where the interaction zone contains coarse silica particles as well, or is conspicuously absent.

The average body composition of: $\mathrm{SiO}_{2}-94.5 \%$; $\mathrm{Na}_{2} \mathrm{O}-1.2 \% ; \mathrm{K}_{2} \mathrm{O}-0.7 \%$; $\mathrm{CaO}-0.7 \%$; $\mathrm{MgO}-0.5 \% ; \mathrm{Al}_{2} \mathrm{O}_{3}-$ $1.8 \%$; and $\mathrm{FeO}-0.6 \%$ is consistent with their stonepaste character. The glaze layers of these samples are generally 350-500 microns thick, but are thinner in LF-02, LF-04 and LF-06 where they are of the order of $\mathbf{2 5 0}$ microns or so. The glaze overflow features detected on the Makli tiles are notably absent here, the uniformity in thickness of the glaze layer up to the edges of these tiles implying that they were probably cut from larger-sized specimens. This would certainly have been the most economical approach, given that the individual finished tile pieces were of a fairly small size, and were often modelled in complex shapes.

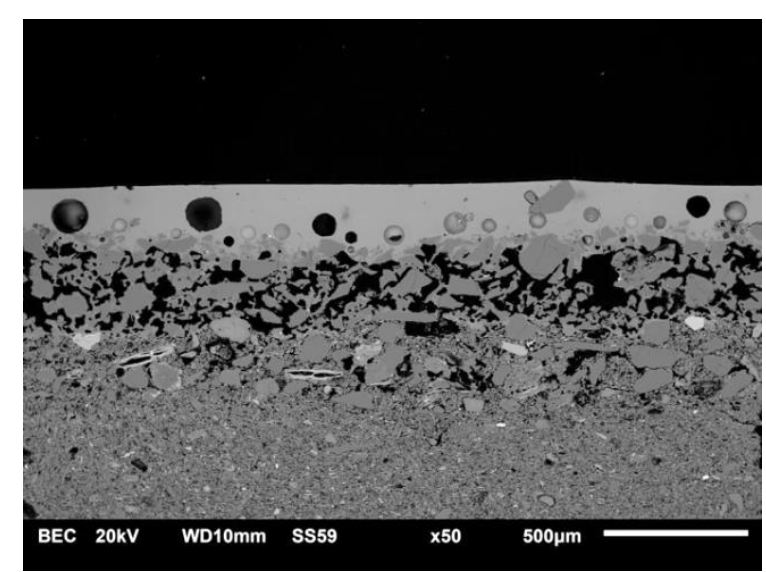

Figure 5. SEM photomicrograph of a turquoise coloured Makli tile (MA-22) in section. The slip layer of fine particles seen between the body below, and the bright glaze layer on top, is typical of samples from this site. Note the pristine state of the glaze, a feature common to almost all the samples.

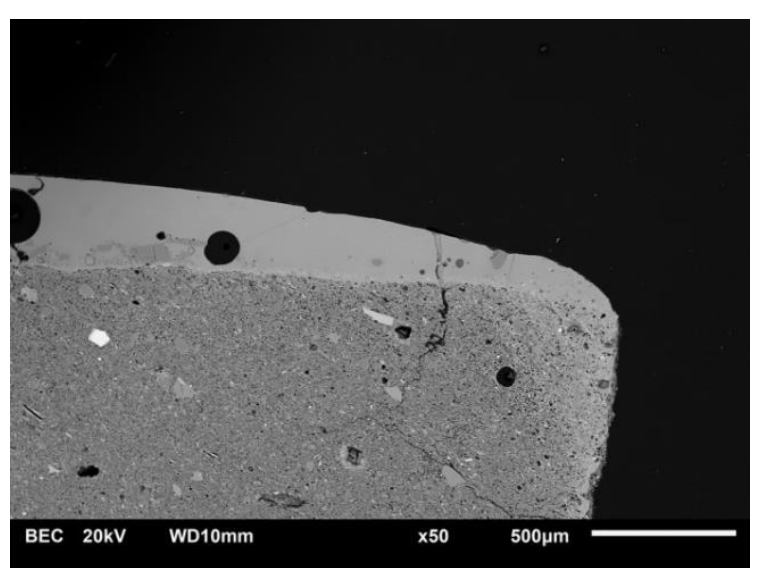

Figure 6. SEM photomicrograph of a white coloured Makli tile (MA-07) illustrating the downward sloping of the glaze towards the edges. Some of the glaze in this case can be seen to have overflowed over the edge, on to the side. 


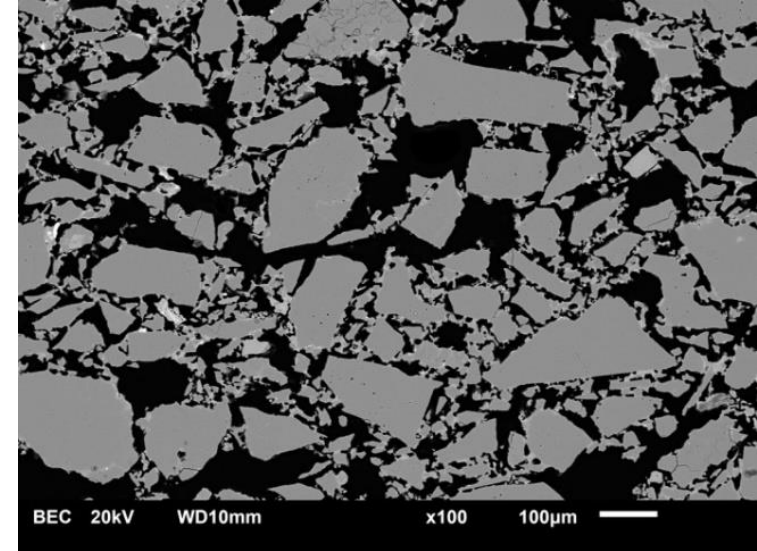

Figure 7. SEM photomicrograph of a Lahore Fort tile body (LF-03) showing it to be almost entirely composed of silica particles, and not clay minerals. The black areas are pores.

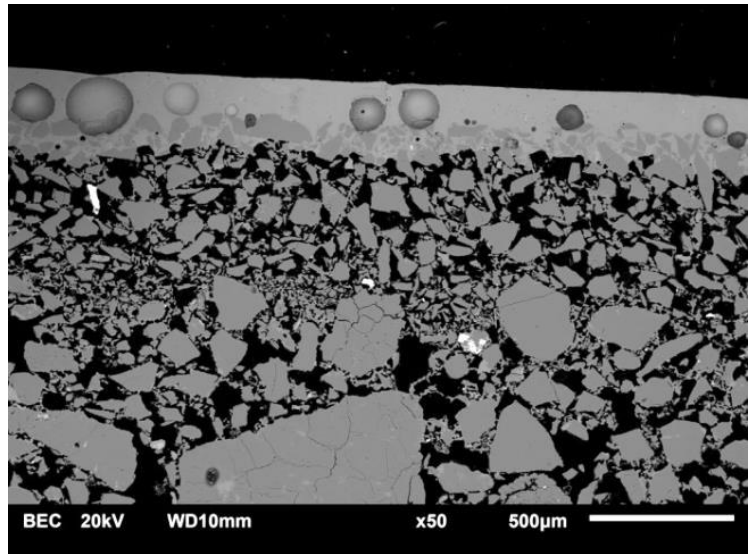

Figure 8. SEM photomicrograph of a dark-blue coloured Lahore Fort tile (LF-04) in section, illustrating its stratigraphy. A slip layer is clearly noticeable here, distinguished from the body by the smaller size of its particles.

\section{Glazes and colorants}

As opposed to the distinctions noted for their bodies, the Makli and Lahore glazes are found to be compositionally similar, both being of the silica-lime-soda type (Tables 1 and 2). The reduced (colorant-free) magnesia and potash contents (SOM Tables S1 and S2), typically 3-3.5 wt\% for each, imply that a plant ash flux was used. Within these broad similarities, there are some variations in the glaze compositions between the two sites. Soda is consistently lower in the MA samples, averaging around $13 \%$, compared to $17-18 \%$ for the LF specimens. Lime is conversely higher in the MA samples, averaging around $6 \%$, compared to around $4.5 \%$ for the LF samples. Potash and magnesia values are mostly comparable in individual samples, although they are together marginally higher by about $0.5 \%$ in the MA samples as opposed to those from LF. Alumina varies more across the LF samples, ranging over 1.5-3.5\%, but otherwise mostly lies between 2-2.5\% for samples from both the regions. Iron oxide contents are slightly enhanced in the MA samples over those from LF, averaging $1.3 \%$ and $1.1 \%$ respectively. Titania, measured at an average of $0.3 \%$ in the MA samples, is constantly below the detection limit (c. $0.3 \mathrm{wt} \%$ ) of the instrument for the LF samples. Silica typically lies in the range of 65$70 \%$, varying inversely with soda and being accordingly higher in the Makli samples.

Among the Makli samples, MA-12, MA-13, and MA-18 are notably different from the standard. Their unusually low magnesia contents and the presence of significant quantities of lead oxide (in the case of MA-13 Dark-Blue/White/Turquoise, and MA-18 Turquoise) indicate that they were differently prepared, and are probably representative of some later restoration effort. Lead oxide is otherwise only determined in the yellow, green, and orange LF glazes, where it is due to the colorant employed.

The compositional similarities between the samples extend to the colorants. The three glaze colours common to the MA and LF samples (turquoise, dark-blue, and white) are all coloured in the same manner, although the techniques of applying or adding the pigments is likely to have been different for the monochrome and polychrome glazes. The three additional colours that are specific only to the LF glazes (yellow, orange, and green) are all based on lead stannate (lead-tin yellow) in one way or the other.

\section{Turquoise}


211 All turquoise tiles and areas are coloured by c. 2-6 wt\% copper oxide, with varying concentrations 212 resulting in the tonal variations noticeable between different individual tiles of this colour. Pigment 213 concentrations across individual glaze layers at the same time are clearly more consistent in the 214 monochrome glazes as compared to the polychrome glazes, the same feature observed for the dark215 blue glazes too.

216 Dark-blue

217 The dark-blue glazes are all coloured by $0.5-1$ wt\% cobalt oxide. Cobalt oxide is also detected in the 218 dark-blue coloured areas on the MA polychrome glazes, but in relatively higher concentrations, more 219 often in excess of $1 \%$ and up to as high $2 \%$. This indicates underglaze-painting on these tiles, since 220 such high quantities would otherwise not be needed to attain a dark-blue shade. A few small bright 221 particles suspended in some of these glazes are cobalt-rich with some associated nickel, iron, and 222 arsenic contents. Arsenic oxide is accordingly detected in the bulk compositions of the dark-blue glazes 223 only. A newly-formed arsenic-rich phase with significant calcium and little or no cobalt content 224 frequently appears in many of these glazes as bright small grains scattered among the silica particles 225 in the glaze-slip interaction zone. This phase probably formed inadvertently by the volatilization of 226 some arsenic associated with the cobalt pigment during the melting of the glaze, and its combining 227 with some lime in the batch to form a stable calcium arsenate compound.

\section{White}

229 No colorant is found in the white MA and LF glazes, the white colour apparently resulting from the use 230 of a white slip below a colourless glaze. The use of the glaze frit by itself, without a colorant, was 231 apparently sufficient to obtain this effect - given that the employment of a silica-rich slip (or body) was 232 an inherent aspect in the production technology of the tiles at both the sites.

Yellow and orange

The yellow and orange LF glazes are both found to contain undissolved particles of the colorant lead stannate dispersed across their glaze layers (Figure 9). Particles in the yellow glazes are the silicacontaining version of lead stannate known as lead-tin yellow Type II (Rooksby 1964, Kuhn 1968, Clark et al. 1995), while those in the orange glazes conform to the lesser-known zinc-containing variant, lead-tin orange (Gill and Rehren 2014).

Green

The green LF glazes contain particles of lead-tin yellow Type II spread across the glaze layers with 2-3 wt\% copper oxide. The colour was therefore achieved by the combination of yellow and blue resulting in green. 


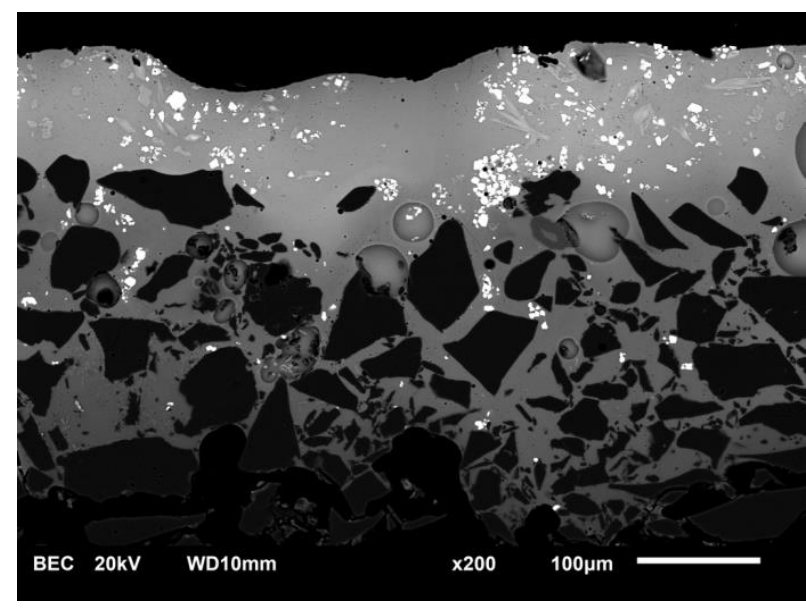

Figure 9. SEM photomicrograph of an orange glaze (LF-06) showing the distribution of lead stannate pigment particles within. Note the clustering associated with the particles.

243

244

245

246

247

248

249

250

251

252

253

254

255

256

257

258

259

260

261

262

263

264

\subsection{Mass spectrometry}

The LA-ICP-MS results for the bulk compositions correlate well with those attained through SEM-EDS (SOM Table S3). ${ }^{1}$ Differences in colorant content can be attributed to the selection of different spots or areas for analysis by the two techniques that were carried out independently of each other, and the varying concentrations of the colorants at these places.

Trace element data shows a general consistency in the distribution of elements for samples from the same building, although some variations are noticeable for glazes of different colours (Table 3). The MA samples together (excluding MA-12, MA-13, MA-18, and MA-21) form a group distinct from the LF specimens through their respective $\mathrm{Li}, \mathrm{Ti}, \mathrm{V}, \mathrm{Cr}, \mathrm{Zn}$, and Ba contents, which are notably higher in the Makli specimens (Li:170-330 ppm, Ti:1020-1950 ppm, V:20-30 ppm, Cr:20-40 ppm, Zn:60-320 ppm, Ba:180-490 ppm) as compared to those from Lahore Fort (Li:30-50 ppm, Ti:440-690 ppm, V:1-10 ppm, $\mathrm{Cr}: 1-10 \mathrm{ppm}, \mathrm{Zn}: 20-40 \mathrm{ppm}, \mathrm{Ba}: 120-170 \mathrm{ppm})$. The other metallic elements, leaving aside the colorants $(\mathrm{Cu}, \mathrm{Co})$ and their correlated elements $(\mathrm{Ni}, \mathrm{As})$, are more homogeneously distributed across the two sample groups. Among these B (160-230 ppm), Mn (310-490 ppm), Rb (30-130 ppm), Sr (260$520 \mathrm{ppm})$, and $\mathrm{Zr}(40-80 \mathrm{ppm})$ are present in appreciable concentrations. Higher than usual Fe values reported for some samples within a group can be related with the enhanced Co contents recorded in the same. MA-12, MA-13, and MA-18, with significant Pb contents, are clear outliers among the MA samples, as determined earlier on the basis of SEM-EDS analysis.

\section{DISCUSSIONS}

\subsection{The body fabrics}

The tiles at the two sites were differently made, although some commonalities are also apparent in their production. The Makli tiles have earthenware or terracotta bodies, comprising little other than

\footnotetext{
${ }^{1}$ The few noticeable variations in the major/minor oxides (MA-13; CaO, MA-18; FeO, and LF-02; CaO) seem to be on account of some limitations associated with the techniques employed. For instance, the lime contents of LF-02 as measured by LA-ICP-MS is 5.7\%, while the corresponding figure recorded through SEM-EDS is about a third less. The higher reading for LA-ICP-MS in this case is most likely due to the unusual high presence of limerich crystal phases in the glaze layer of this sample, and the difficulties associated in deliberately avoiding such inclusions while measuring by this technique as compared to the SEM-EDS system.
} 
clay that has been worked to a fine degree prior to firing. Such bodies are also used in modern kashi ware being manufactured in Sindh (notably at Hala) and Multan (Rye and Evans 1976, 107-108, Akhund and Askari 2011, UNESCO 2015). The clay used for the Makli tiles would doubtless have been procured locally, most likely in the vicinity of where they were being manufactured. The sophistication of the body finish further indicates that the clay or clays were of a particularly fine quality, with care being taken to ensure that minor grit or impurities were removed prior to the modelling stage. The use of just well-prepared clay by itself for the preparation of the bodies, with little or no temper, is reported for current traditional practice as well (Rye and Evans 1976, 107-108).

The stonepaste Lahore Fort tile bodies on the other hand follow the technology that was dominant elsewhere in the northern part of the Indian subcontinent in Mughal times (Gill and Rehren 2011, Gulzar et al. 2013, Gill et al. 2014). Their microstructural characteristics are consistent with Abu'l Qasim's historical recipe (Allan 1973), with the bodies being typically prepared using about eight to nine parts of silica-rich quartz, and half to one part each of glass frit and/or clay. The presence of two body groups among these samples, distinguished by the shape and distribution of the quartz particles in each, suggests that more than one workshop was involved in the production of these tiles, or that they were produced at two different times in the history of the building.

\subsection{Glaze recipes}

The plant ash glaze of the Makli and Lahore Fort tiles is a feature they share with 17th century specimens from Jahangir's tomb in Lahore (Gulzar et al. 2013), and with coeval Mughal tiles in the Indian Punjab (Gill and Rehren 2011, Gill and Rehren 2014). A similar plant ash-based technology for glaze and glass production is also known to have prevailed in the central Islamic lands, to the west and north of Pakistan, through medieval to pre-modern times (Brill 1999, 482-484, Fabbri et al. 2002, Vandiver et al. 2010, Gradmann et al. 2014). In contrast, tile glazes made in the same period to the east, notably at Delhi and beyond, are predominantly of the mineral soda 'Indian' variety (Gill et al. 2014). This indicates that the geographic expanse of plant ash glass- or glaze-making technologies, otherwise typically associated with the core Islamic lands only, includes the larger region around these two sites as well, and by extension probably the whole of Pakistan. Ethnographic studies conducted in Sindh and Punjab over the last century and a half further suggest that the glaze frit is likely to have been prepared in the manner ascribed to a particular traditional practice in the region (Hallifax 1892, Rye and Evans 1976, pp. 95-96), through the manufacture of glass balls in a furnace, which were then broken down and milled to obtain a glaze powder. This seems to be the case at least for the SindhMultan kashi variety of tiles. Certainly no evidence for local glaze manufacture by the typical method of melting glass in a furnace and its subsequent pouring in water, as reported for other places in the Islamic world, has yet come to light.

Silica (quartz) and plant ash soda would have been used as the raw material for the production of the frit. The plant ash is likely to have been obtained by the burning of Haloxylon recurvum (Haloxylon stocksii), a local desert plant, and a known common source for crude soda in the region (Tite et al. 2006). Silica would probably have been similarly derived as for the bodies, and/or slips, for the Lahore and Makli tiles respectively. Chemical compositions and trace element patterns indicate that the silica is likely to have been drawn from different geological sources for the two sites. Relatively lower values of the heavy accessory minerals (as indicated by levels of $\mathrm{Fe}, \mathrm{Ti}, \mathrm{Ba}$ ), together with the general roundedness of the quartz grains in the Lahore Fort body matrices, suggest the employment of a 
mature high silica sand in their case. A different source was used for the Makli tiles. The higher contents of these elements, notably the elevated titania and iron oxide levels, may be suggestive of silica derived from quarried quartz (deposits), as recorded for current traditional practice in the region.

Differences in the soda contents of the glazes suggest that either different proportions or different varieties of the two ingredients were utilized at the two places (Fig. $10 \mathrm{Na}_{2} \mathrm{O}$ vs $\mathrm{CaO}$ ). The Lahore tiles, with average soda contents of around $18 \mathrm{wt} \%$, are likely to have been produced using roughly equal parts of silica (quartz) and soda (plant ash), as described in Abu'I Qasim's historical recipe, whereas the Makli tiles that are typically $5 \mathrm{wt} \%$ or so lower in soda, probably used a higher proportions of silica. The differences in the soda values could, however, also indicate the use of different plant species, as further indicated by the differences in trace alkalis lithium and rubidium (Fig. $11 \mathrm{Li}$ vs Rb), or the use of different techniques to obtain and refine plant ash at the two places.

Five of the Makli tiles fall away from the main group: MA-12 and MA-13 with very low $\mathrm{CaO}$ and $\mathrm{MgO}$ values; MA-14 and MA-18 with relatively low lime and soda levels, and MA-21 with very high soda (see Fig. $10 \mathrm{Na}_{2} \mathrm{O}$ vs $\mathrm{CaO}$ and Table \#). We have trace element analyses of four of these samples (MA12, MA-13, MA-18, and MA-21) which show that they also differ in other characteristics, such as low arsenic for the two cobalt-blue samples MA-12 and -13 compared to other cobalt-blue samples (MA4, $-5,-16$ and -27). Three of these (MA-12, MA-13, and MA-18) are characterised by significantly high boron values (2000-8150 ppm - ten to forty times more than the average of the remaining Makli tiles; Table 3), very high lead (particularly in MA-13 and MA-18 where it is a few hundred times more in ppm than the others), low strontium (80 to $160 \mathrm{ppm}$, compared to typically 250 to $400 \mathrm{ppm}$ for the other Makli samples), and very low manganese (75-120 ppm, only a third to a fifth of the levels seen in the other tiles). It is possible that these tiles represent a different production group, and are likely to be later repairs, although they do appear overall similar to the main samples in that they, too, seem to be plant-ash based and using a silica source with similar concentrations of accessory minor oxides, and their bodies and manufacture do not show any major differences from the remaining tiles. The high boron values associated with some of these can be related to the reported use of borax for a secondary refinement of glazes in traditional local manufacture from the late 19th century onwards (Birdwood 1884, 401, Rye and Evans 1976, 96), reiterating the suggestion that these are more likely to be resultant of some later date restoration effort.

The SEM-EDS bulk glaze analyses indicated that the glazes from Makli and Lahore Fort have two slightly distinct compositions, most markedly in their soda and lime content; the trace element data make this separation even more clear, with distinct differences in a number of elements which can be linked to the flux of the glaze ( $\mathrm{Li}, \mathrm{B}, \mathrm{Cl}, \mathrm{Rb})$ as well as to the silica source ( $\mathrm{Ti}, \mathrm{Sr}, \mathrm{Ba}$, REEs). These consistent and significant differences further underline the co-existence of two distinct glazed tile manufacturing traditions which were already indicated by the sharp difference in body composition.

The turquoise glaze on sample MA-21, badly preserved on a clay-based body which is indistinguishable from the other Makli tile bodies, shares many chemical characteristics with the Lahore Fort glazes. This includes the very high soda and chlorine levels as well as rather low lithium and rubidium content (see Fig. 11) Since little is known about the tomb from which this tile originates it is not possible to speculate about potential reasons for this combination of local clay-based tile body with a Lahoretype glaze otherwise only found on stonepaste bodies. 


\subsection{Coloration}

350 The glazes were clearly similarly coloured at the two sites, using the same colorants. While the bulk composition of differently coloured areas in the polychrome glazes differ depending on the nature and amount of colorants added, it is important to stress that the reduced compositions, that is the composition of these glazes without the added colorants and re-cast to $100 \mathrm{wt} \%$, are identical within analytical uncertainty and normal variability across all colours. Thus, we are confident to say that for the production of polychrome tiles the different colorants were added to one and the same base glass, and that no pre-coloured glaze frit mixtures were procured from different sources using different base glass recipes. The 14th century sample (MA-20), and one dating to the 17th century (MA-19), were also found to be coloured in the same manner. The colorants employed are consistent with those known from pre-modern glazes in the subcontinent (Gill and Rehren 2011, Gulzar et al. 2013, Gill et al. 2014). The turquoise, dark-blue, and white glazes that are common to the two sites are thus coloured using copper oxide, cobalt oxide, and through a white slip/body respectively, while the yellow and green glazes of Lahore Fort are coloured with lead stannate and lead stannate + copper oxide respectively. The orange Lahore Fort glazes are coloured by the same zinc-containing variant of lead stannate as found in their counterparts in Indian Punjab, corroborating the other evident connections in the technologies of the two.

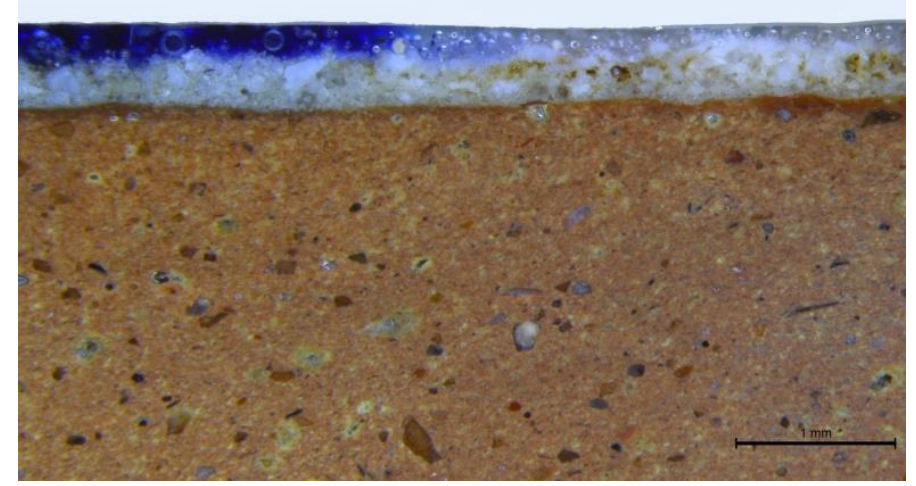

Figure 102. Optical microscopy image of the blue and white coloured areas of a polychrome Makli glaze (MA-10). Note the extent of coloration of the glaze in the dark-blue zone.

Analytical findings confirm that the polychrome tiles, which are specific to Makli only, were underglaze-painted, the pigments seemingly being first painted on the slips and then a transparent glaze applied-on. The silica-rich slip that was typically applied on these bodies apparently performed three functions; it provided an even surface for painting where needed, effectively masked the redness of the underlying terracotta body, and produced a white background where left unpainted and covered with a transparent glaze. The monochrome specimens from the two sites, in contrast, are more likely to have had only a single stage involved for the coloration of their glazes, with the pigments being dry-mixed into the glaze powder beforehand, as usually done in traditional practice. This is supported to an extent by the general clustering noticeable for the undissolved pigment particles that lie suspended in the lead stannate coloured glazes, while a more even distribution would be expected in the case of pre-coloured frits. It is interesting to see that no clearly defined separate 
layer of a transparent glaze is visible over the body in the case of the polychrome tiles (Figure 12), the pigments apparently having worked their way into the glazes and colouring them through their entire thicknesses at the time of melting. The noted variations in pigment concentrations in the coloured zones of these tiles individually, however again makes a case for these being underglaze-painted, as opposed to suggesting the use of a coloured frit or glaze.

\subsection{Comparison to contemporary practice}

While the kashi tile-work now being produced at Sindh and Multan by and large utilize the same glaze preparation and colouring techniques as determined for the Makli tiles, some changes to the glaze and glazing recipes seem to have been introduced over time. The consistent use of lead glazes since the last century or so for instance (Birdwood 1884, 401, Hallifax 1892, 16-17, Furnival 1904, 225, Rye and Evans 1976, 109-110), in addition to alkaline glazes, does not seem to have any historical parallel, and no such glazes have been found so far in the examined corpus of historical samples (other than the obvious outliers which are probably a restoration effort, as stated earlier). The use of borax for a secondary refinement of the raw glaze frit at Multan, or the use of different coloured slips at Hala in Sindh likewise (Rye and Evans 1976, 109-110), appear to be technological alterations that have arrived at a relatively more modern date. It is therefore seen that only a part of the technologies that are being currently followed in traditional practice in Sindh-Multan can be related to the historic tile-work originally employed on monuments in the region. These identified technologies are likely to be more appropriate for conservation programmes that may be initiated for the tile-work from time to time. It is worth mentioning in this context that a remarkably accurate rendition of the same technologies were apparently employed in the restoration of the tile-work on Shaikh Rukn-e-Alam's tomb at Multan (Khan 1985), undertaken on the orders of the Government of Pakistan-Punjab. The Sindh Makli tiles, should the need arise, may be conserved or restored in broadly the same manner, with suitable modifications being applied based on the findings of this study. For now, it would be appropriate to just state that the Makli tiles can be considered antecedents of the modern traditional kashi ware in so far as materials and technologies are concerned. Further work is needed to correlate historic tiles from elsewhere in Sindh-Multan to the same technological style.

\section{CONCLUSION}

The Makli tiles are different from those from Lahore in their glaze and body compositions, range of glaze colours exhibited, and glaze decoration techniques. They both, however, share the same basic glaze characteristics using plant ash as the main flux, and are more 'Central Asian' or 'Persian' as opposed to being 'Indian' in this respect. The colorants used in all these glazes are consistent with those known to have been employed in the wider region in pre-modern times. In the larger context of Islamic tile-work, the Lahore tiles can be said to be closer in character to those from the central Islamic lands in terms of their overall make-up. Their relatively short duration of employment, and the yet unreported presence of any similar tradition in Pakistan before their appearance, suggests that they were a 'foreign' import, likely executed at the hands of migrant artisans. The Makli kashi tiles in comparison are clearly a more local development, with roots in the Sindh-Multan region. While conforming in spirit and character to the typical Islamic traditions of architectural tiling, they stand apart as being one of few examples of craft practices that has survived and remained steadfast over time. Indeed they are perhaps the only true living representations of the blue-and-white tiling traditions which made their appearance in the Islamic world as early as the 14th century. 
420 The authors are grateful to UNESCO World Heritage Centre, Paris, and the concerned departments of 421 the Governments of Sindh and Punjab in Pakistan for providing the samples for this study. Noor Jehan 422 Sadiq and Ar. Ashfaque Ahmed expertly documented the samples and their findspots in their 423 respective buildings from Makli and Lahore Fort. We especially appreciate the personal interest taken 424 by Ms Junhi Han, Programme Specialist at UNESCO Paris, for making this study possible. The Heritage 425 Foundation of Pakistan is thanked for making available the detailed documentation accompanying the 426 samples. Dr. Bernard Gratuze and IRAMAT CEB, CNRS Orléans, are thanked for the LA-ICP-MS analyses. 427 Khaleda Akhtar is acknowledged for preparing the samples for SEM-EDS analyses at UCL Qatar. The 428 generous support of Qatar Foundation funding UCL Qatar and its Archaeological Materials Science 429 Laboratories is gratefully acknowledged. 


\section{References}

Akhund, A. H. \& Askari, N. 2011. Tale of the tile: The ceramic traditions of Pakistan. Karachi, Mohatta Palace Museum.

Allan, J. W. 1973. Abu'I Qasim's treatise on ceramics. Iran, 11, 111-120.

Birdwood, G. C. M. 1884. The industrial arts of India, Part II. London, Chapman and Hall.

Brill, R. H. 1999. Chemical analyses of early glasses, v. 2. New York, Corning.

Carswell, J. 1998, Iznik Pottery, London: The British Museum Press.

Clark, R., Cridland, L., Kariuki, B. \& Withnall, R. 1995. Synthesis, structural characterisation and Raman spectroscopy of the inorganic pigments lead tin yellow types I and II and lead antimony yellow: Their identification on medieval paintings and manuscripts. Journal of the Chemical Society, Daltons Transactions, 2577-82.

Cousens, H. 1906. Portfolio of illustrations of Sind tiles. London, W. Griggs and Sons.

Cousens, H. 1929. The antiquities of Sind with historical outline. Calcutta, Archaeological Survey of India, New Imperial Series, Vol. XLVI.

Degeorge, G. \& Porter, Y. 2002. The art of the Islamic tile. Paris, Flammarion.

Delange, E., 2015, Le décor de palais de Séthi ler - Porte(s) de Qantir, in: E. Delange (Hg.), Monuments Égyptiens du nouvel empire, Paris, 187-283.

Fabbri, B., Gualtieri, S. \& Mingazzini, C. 2002. Material and techniques of the ceramic wall facings in the Timurid necropolis of Shahi Zinda (Samarkand, Uzbekistan). Modern trends in scientific studies on ancient ceramics, BAR International Series, 1011, 351-360.

Friedman, F.D. 1998. Gifts of the Nile: ancient Egyptian faience. Thames and Hudson, London.

Furnival, W. J. 1904. Leadless decorative tiles, faience, and mosaic. Staffordshire.

Gill, M. S. \& Rehren, Th. 2011. Material characterization of ceramic tile mosaic from two 17th century Islamic monuments in northern India. Archaeometry, 53 (1), 22-36.

Gill, M. S. \& Rehren, Th. 2014. The intentional use of lead-tin orange in Indian Islamic glazes and its preliminary characterization. Archaeometry, 56 (6), 1009-1023.

Gill, M. S., Rehren, Th. \& Freestone, I. 2014. Tradition and indigeneity in Mughal architectural glazed tiles. Journal of Archaeological Science, 49, 546-555.

Gradmann, R., Badr, J. \& Schuessler, U. 2014. Characterisation of glazed tiles with EPMA and Mobile XRF for the development of adapted conservation materials. Proceedings of the 39th International Symposium for Archaeometry, Leuven (2012), 208-214.

Gratuze, B., 2013. Glass characterisation using laser ablation inductively coupled plasma mass spectrometry methods. In: Janssens, K. (Ed.), Modern Methods for Analysing Archaeological and Historical Glass 1. John Wiley and Sons Ltd, Chichester, pp. 201-232. 
Grazhdankina, N.S., Rakhimov, M.K and Pletnev, I.E. 2006. Architectural Ceramics of Uzbekistan. UNESCO, Tashkent.

Gulzar, S., Worle, M., Burg, J., Chaudhry, M. N. \& Joseph, E. 2013. Characterization of 17th century Mughal tile glazes from Shahdara complex, Lahore-Pakistan. Journal of Cultural Heritage, 14, 174-179.

Hallifax, C. J. 1892. Monograph on the pottery and glass industries of the Punjab 1890-91. Lahore, The Civil and Military Gazette Press.

Khan, A. N. 1990. Islamic architecture of Pakistan: An analytical exposition. Islamabad, National Hijra Council.

Khan, M. W. U. 1985. Mausoleum of Shaikh Rukn-e-Alam, Multan. Lahore, Wajidalis Limited.

Kuhn, H. 1968. Lead-tin yellow. Studies in Conservation, 13, 7-33.

UNESCO 2015. Revival of ancient kashi in Sindh. Unpublished report, UNESCO/Republic of Korea FiT Project on "World Heritage, Sustainable Development and Community Involvement". Lari, Y., Heritage Foundation, Karachi 2015. [accessed 12 Nov 2016]. Available at http://www.heritagefoundationpak.org/Page/14443/UNESCO-Project-Revival-of-Ancient-Kashi-inSindh-Research-Document.

Matson, R, 1986: Glazed bricks from Babylon - historical setting and microprobe analyses. In: W.D. Kingery et al. (eds.), Ceramics and Civilization 2, 133-156.

Paynter, S. 2008: Links between glazes and glass in mid-2nd millennium BC Mesopotamia and Egypt. In: A. Shortland, I. Freestone and Th. Rehren (eds.), From Mine to Microscope, 93-108. Oxbow Books, Oxford.

Porter, V. 1995 Islamic Tiles. British Museum Press.

Rehmani, A. 1997-98. The Persian glazed tile revetment of Mughal buildings in Lahore. Lahore Museum Bulletin 10-11, 74-98.

Rooksby, H. P. 1964. A yellow cubic lead tin oxide opacifier in ancient glasses. Physics and Chemistry of Glasses, 5 (1), 20-25.

Rye, O. S. \& Evans, C. 1976. Traditional pottery techniques of Pakistan: field and laboratory studies. Washington D.C., Smithsonian Institution Press.

Tite, M. S., Shortland, A., Maniatis, Y., Kavoussanaki, D. \& Harris, S. A. 2006. The composition of the soda-rich and mixed alkali plant ashes used in the production of glass. Journal of Archaeological Science, 33, 1284-1292.

Vandiver, P. B., Vandiver A., Rakhimov, A. \& Rakhimov, A. 2010. Ishkor glazes of Uzbekistan. In: Neville, A. (ed.) Conservation of Ancient Sites on the Silk Road : Proceedings of the Second International Conference on the Conservation of Grotto Sites, Mogao Grottoes, Dunhuang, People's Republic of China, June 28-July 3, 2004. Los Angeles: The Getty Conservation Institute.

Vogel, J. Ph. 1920. Tile-mosaics of the Lahore Fort. Calcutta, Archaeological Survey of India. New 
Imperial Series, Vol. XLI. 
Table 1. Chemical compositions of the Makli tile glazes determined through SEM-EDS analyses. All results are in wt\% and normalised to $100 \%$. Results below the detection limit of the instrument are provided for comparative purposes only. '-' indicates 'not detected'.

\begin{tabular}{|c|c|c|c|c|c|c|c|c|c|c|c|c|c|c|c|c|c|}
\hline Sample & Type & Glaze colours & $\mathrm{SiO}_{2}$ & $\mathrm{Na}_{2} \mathrm{O}$ & $\mathrm{CaO}$ & $\mathrm{K}_{2} \mathrm{O}$ & MgO & $\mathrm{Al}_{2} \mathrm{O}_{3}$ & $\mathrm{FeO}$ & $\mathrm{TiO}_{2}$ & $\mathrm{P}_{2} \mathrm{O}_{5}$ & $\mathrm{SO}_{3}$ & $\mathrm{Cl}$ & $\mathrm{CuO}$ & $\mathrm{CoO}$ & $\mathrm{As}_{2} \mathrm{O}_{3}$ & $\mathrm{PbO}$ \\
\hline MA-01 & Polychrome & Dark-Blue, White, Turquoise & 64.3 & 14.4 & 5.6 & 3.0 & 3.1 & 2.5 & 1.6 & 0.2 & 0.4 & 0.4 & 0.5 & 1.7 & 1.4 & 1.0 & - \\
\hline MA-02 & Polychrome & Dark-Blue, White, Turquoise & 66.9 & 12.6 & 6.8 & 3.5 & 3.6 & 1.9 & 1.0 & 0.2 & 0.4 & 0.3 & 1.2 & 0.9 & 0.6 & - & - \\
\hline MA-03 & Monochrome & Turquoise & 69.5 & 10.5 & 5.8 & 3.9 & 3.2 & 2.7 & 1.1 & 0.2 & 0.4 & 0.4 & 0.1 & 2.1 & - & - & - \\
\hline MA-04 & Polychrome & Dark-Blue, White, Turquoise & 64.8 & 13.8 & 5.3 & 2.6 & 3.0 & 2.4 & 1.5 & 0.2 & 0.4 & 0.3 & 0.5 & 3.3 & 1.0 & 0.8 & - \\
\hline MA-05 & Monochrome & Dark-Blue & 65.3 & 14.3 & 6.6 & 2.9 & 3.8 & 2.8 & 1.7 & 0.3 & 0.5 & 0.4 & 0.4 & - & 0.7 & 0.6 & - \\
\hline MA-06 & Monochrome & Turquoise & 63.6 & 12.9 & 6.0 & 3.1 & 3.6 & 2.6 & 1.0 & 0.2 & 0.4 & 0.3 & 0.5 & 5.6 & - & - & - \\
\hline MA-07 & Monochrome & White & 65.7 & 14.5 & 6.8 & 2.9 & 4.1 & 2.9 & 1.3 & 0.2 & 0.5 & 0.4 & 0.5 & - & - & - & - \\
\hline MA-08 & Monochrome & Turquoise & 70.0 & 11.5 & 4.9 & 3.0 & 3.1 & 2.6 & 1.1 & 0.2 & 0.2 & 0.2 & 0.8 & 2.4 & - & - & - \\
\hline MA-09 & Monochrome & White & 66.4 & 13.4 & 7.3 & 3.0 & 4.3 & 2.8 & 1.2 & 0.2 & 0.6 & 0.4 & 0.3 & - & - & - & - \\
\hline MA-10 & Polychrome & Dark-Blue, White & 65.9 & 11.6 & 6.1 & 3.9 & 3.6 & 3.2 & 1.8 & 0.3 & 0.6 & 0.2 & 0.4 & 0.2 & 1.3 & 0.8 & - \\
\hline MA-11 & Polychrome & Dark-Blue, White, Turquoise & 68.6 & 10.5 & 5.8 & 3.7 & 3.5 & 2.4 & 1.5 & 0.3 & 0.3 & 0.3 & 0.3 & 1.6 & 0.8 & 0.6 & - \\
\hline MA-12 & Polychrome & Dark-Blue, White, Turquoise & 73.5 & 15.1 & 1.4 & 3.3 & 0.3 & 2.0 & 0.7 & 0.2 & - & 0.6 & 0.1 & 1.8 & 1.0 & - & - \\
\hline MA-13 & Polychrome & Dark-Blue, White, Turquoise & 63.6 & 11.0 & 1.8 & 3.5 & 0.4 & 2.1 & 0.7 & 0.2 & - & 0.1 & 0.5 & 2.0 & 1.0 & - & 13.1 \\
\hline MA-14 & Polychrome & Dark-Blue, White & 71.1 & 6.1 & 3.8 & 5.1 & 2.4 & 5.9 & 1.9 & 0.4 & 0.3 & 0.3 & 0.1 & 0.3 & 2.0 & 0.3 & - \\
\hline MA-15 & Monochrome & Turquoise & 68.5 & 9.7 & 5.9 & 3.7 & 3.8 & 2.7 & 1.1 & 0.3 & 0.4 & 0.3 & 0.5 & 3.0 & - & - & - \\
\hline MA-16 & Polychrome & Dark-Blue, White, Turquoise & 68.8 & 9.2 & 6.2 & 4.0 & 3.8 & 2.2 & 1.1 & 0.3 & 0.2 & 0.3 & 0.2 & 2.9 & 0.7 & 0.2 & - \\
\hline MA-17 & Polychrome & Dark-Blue, White & 69.1 & 11.7 & 6.6 & 3.5 & 3.9 & 2.5 & 1.2 & 0.3 & 0.3 & 0.3 & 0.2 & - & 0.3 & 0.2 & - \\
\hline MA-18 & Monochrome & Turquoise & 66.5 & 10.6 & 3.9 & 3.4 & 0.7 & 2.0 & 1.0 & 0.2 & 0.1 & 0.2 & 0.1 & 4.1 & - & - & 7.2 \\
\hline MA-19 & Polychrome & Dark-Blue, White, Turquoise & 69.5 & 9.6 & 5.4 & 4.0 & 3.4 & 2.2 & 1.0 & 0.3 & 0.2 & 0.3 & 0.3 & 2.9 & 0.4 & 0.4 & - \\
\hline MA-20 & Monochrome & Turquoise & 65.9 & 10.7 & 5.8 & 4.3 & 3.5 & 3.1 & 1.2 & 0.3 & 0.4 & 0.3 & 0.7 & 4.0 & - & - & - \\
\hline MA-21 & Monochrome & Turquoise & 60.4 & 20.1 & 4.0 & 2.2 & 2.9 & 2.5 & 1.2 & 0.3 & 0.3 & 0.3 & 1.7 & 4.2 & - & - & - \\
\hline MA-22 & Monochrome & Turquoise & 67.5 & 10.0 & 5.3 & 3.8 & 2.7 & 2.9 & 1.3 & 0.3 & 0.4 & 0.3 & 0.6 & 5.0 & - & - & - \\
\hline MA-23 & Monochrome & Turquoise & 69.3 & 8.8 & 5.3 & 5.8 & 3.5 & 2.6 & 1.1 & 0.3 & 0.3 & 0.3 & 0.1 & 2.6 & - & - & - \\
\hline MA-24 & Monochrome & Turquoise & 67.2 & 12.3 & 6.0 & 3.0 & 3.8 & 2.7 & 1.1 & 0.3 & 0.3 & 0.2 & 0.6 & 2.6 & - & - & - \\
\hline MA-25 & Monochrome & Turquoise & 64.8 & 13.8 & 7.1 & 2.5 & 3.8 & 3.3 & 1.6 & 0.3 & 0.4 & 0.3 & 0.4 & 1.8 & - & - & - \\
\hline MA-26 & Polychrome & Dark-Blue, White, Turquoise & 68.5 & 10.5 & 5.3 & 3.4 & 3.6 & 2.2 & 0.9 & 0.2 & 0.3 & 0.3 & 0.1 & 4.9 & - & - & - \\
\hline MA-27 & Polychrome & Dark-Blue, White & 69.2 & 9.6 & 6.3 & 3.4 & 4.2 & 2.8 & 1.2 & 0.3 & 0.3 & 0.3 & 0.5 & 0.3 & 0.9 & 0.7 & - \\
\hline MA-28a & Monochrome & Turquoise & 68.7 & 10.2 & 5.8 & 3.4 & 3.6 & 1.9 & 0.9 & 0.2 & 0.3 & 0.3 & 0.4 & 4.2 & - & - & - \\
\hline MA-28b & Monochrome & Dark-Blue & 67.8 & 10.0 & 6.4 & 3.8 & 3.8 & 2.9 & 1.7 & 0.3 & 0.3 & 0.4 & 0.2 & 0.3 & 1.1 & 0.8 & - \\
\hline
\end{tabular}


Table 2. Chemical compositions of the Lahore Fort tile glazes determined through SEM-EDS analyses. All results are in wt\% and normalised to $100 \%$. '-' indicates 'not detected'.

\begin{tabular}{|c|c|c|c|c|c|c|c|c|c|c|c|c|c|c|c|c|c|}
\hline Sample & Type & Glaze colour & $\mathrm{SiO}_{2}$ & $\mathrm{Na}_{2} \mathrm{O}$ & $\mathrm{CaO}$ & $\mathrm{K}_{2} \mathrm{O}$ & MgO & $\mathrm{Al}_{2} \mathrm{O}_{3}$ & $\mathrm{FeO}$ & $\mathrm{P}_{2} \mathrm{O}_{5}$ & $\mathrm{SO}_{3}$ & $\mathrm{Cl}$ & $\mathrm{CuO}$ & $\mathrm{CoO}$ & $\mathrm{ZnO}$ & $\mathrm{SnO}_{2}$ & $\mathrm{PbO}$ \\
\hline LF-01 & Monochrome & Yellow & 55.2 & 12.2 & 2.8 & 6.0 & 2.1 & 1.5 & 0.6 & 0.3 & - & 0.7 & - & - & 0.4 & 3.7 & 14.4 \\
\hline LF-02 & Monochrome & White & 64.6 & 19.2 & 3.6 & 3.3 & 3.3 & 2.7 & 1.1 & 0.5 & 0.6 & 1.3 & - & - & - & - & - \\
\hline LF-03 & Monochrome & Dark Blue & 65.5 & 17.4 & 5.0 & 2.8 & 2.9 & 2.3 & 1.9 & 0.3 & 0.5 & 0.7 & - & 0.8 & - & - & - \\
\hline LF-04 & Monochrome & Dark Blue & 65.4 & 16.5 & 4.7 & 3.3 & 3.1 & 3.4 & 1.2 & 0.4 & 0.4 & 1.2 & - & 0.4 & - & - & - \\
\hline LF-05 & Monochrome & Turquoise & 65.1 & 16.0 & 5.4 & 2.4 & 3.1 & 2.0 & 0.7 & 0.4 & 0.5 & 0.9 & 3.8 & - & - & - & - \\
\hline LF-06 & Monochrome & Orange & 50.1 & 12.0 & 3.1 & 2.5 & 2.2 & 1.5 & 0.6 & 0.3 & - & 0.9 & - & - & 1.9 & 5.6 & 19.5 \\
\hline LF-07a & Monochrome & Green & 55.9 & 14.2 & 3.3 & 3.3 & 2.5 & 2.0 & 0.9 & 0.3 & - & 0.9 & 2.2 & - & - & 3.3 & 11.3 \\
\hline LF-07b & Monochrome & Yellow & 52.9 & 18.1 & 3.9 & 2.4 & 2.6 & 1.8 & 0.7 & 0.3 & - & 1.3 & - & - & - & 2.0 & 13.9 \\
\hline LF-08 & Monochrome & Green & 52.2 & 15.1 & 4.2 & 2.4 & 2.8 & 2.1 & 0.8 & 0.3 & - & 1.1 & 2.8 & - & - & 3.2 & 13.1 \\
\hline
\end{tabular}


Table 3. Trace element compositions of select Makli and Lahore glazes determined through LA-ICP-MS analyses and reported in ppm. Elements that are diagnostic of the two groups are highlighted in bold. The outliers in the Makli group are highlighted in light-gray. 0 ppm indicates values below 0.5 ppm.

\begin{tabular}{|c|c|c|c|c|c|c|c|c|c|c|c|c|c|c|c|c|c|c|c|c|c|c|c|c|}
\hline Sample & Colours analysed & Li & B & $\mathrm{Ti}$ & v & $\mathrm{Cr}$ & $\mathrm{Mn}$ & $\mathrm{Fe}$ & Co & $\mathbf{N i}$ & $\mathrm{Cu}$ & $\mathrm{Zn}$ & As & $\mathbf{R b}$ & $\mathrm{Sr}$ & $\mathbf{Y}$ & $\mathrm{Zr}$ & Sn & Sb & $\mathrm{Ba}$ & La & $\mathrm{Ce}$ & $\begin{array}{l}N \\
d\end{array}$ & $\mathrm{~Pb}$ \\
\hline \multicolumn{25}{|c|}{ Makli samples } \\
\hline MA-01 & Turquoise & 211 & 183 & 1203 & 20 & 15 & 325 & 8108 & 125 & 39 & 19026 & 114 & 163 & 54 & 410 & 7 & 49 & 202 & 25 & 245 & 12 & 22 & 10 & 55 \\
\hline MA-02 & Dark-Blue, White & 215 & 193 & 1111 & 19 & 19 & 414 & 7839 & 2571 & 164 & 4611 & 104 & 229 & 97 & 518 & 7 & 36 & 2 & 3 & 367 & 13 & 24 & 10 & 70 \\
\hline MA-04 & Dark-Blue, White & 328 & 165 & 1271 & 23 & 36 & 308 & 10590 & 3285 & 306 & 1460 & 243 & 2384 & 57 & 383 & 8 & 43 & 3 & 0 & 415 & 14 & 27 & 13 & 59 \\
\hline MA-05 & Dark-Blue & 276 & 211 & 1280 & 26 & 18 & 410 & 11187 & 3115 & 288 & 938 & 148 & 4013 & 72 & 386 & 12 & 40 & 4 & 0 & 490 & 13 & 23 & 10 & 75 \\
\hline MA-08 & Turquoise & 172 & 161 & 1176 & 18 & 18 & 361 & 8471 & 16 & 56 & 17336 & 63 & 63 & 82 & 275 & 6 & 44 & 6 & 8 & 139 & 12 & 22 & 9 & 130 \\
\hline MA-09 & White & 222 & 228 & 1223 & 21 & 19 & 338 & 8237 & 28 & 12 & 219 & 85 & 17 & 69 & 348 & 7 & 79 & 1 & 0 & 319 & 14 & 26 & 11 & 32 \\
\hline MA-12 & $\begin{array}{l}\text { Dark-Blue, White, } \\
\text { Turquoise }\end{array}$ & 266 & 3154 & 1024 & 22 & 25 & 74 & 4366 & 1234 & 35 & 18625 & 294 & 31 & 80 & 84 & 6 & 67 & 2743 & 24 & 242 & 12 & 22 & 9 & 2345 \\
\hline MA-13 & Dark-Blue, Turquoise & 209 & 2004 & 1017 & 22 & 20 & 118 & 5932 & 6440 & 120 & 28817 & 2300 & 70 & 132 & 157 & 6 & 115 & 2052 & 5306 & 358 & 12 & 22 & 9 & $\begin{array}{r}8911 \\
1\end{array}$ \\
\hline MA-16 & $\begin{array}{l}\text { Dark-Blue, White, } \\
\text { Turquoise }\end{array}$ & 204 & 168 & 1387 & 19 & 14 & 444 & 7926 & 3149 & 338 & 23451 & 320 & 964 & 105 & 311 & 8 & 37 & 34 & 7 & 228 & 12 & 23 & 10 & 108 \\
\hline MA-18 & Turquoise & 167 & 8136 & 937 & 17 & 27 & 77 & 4275 & 172 & 43 & 29778 & 3794 & 80 & 59 & 117 & 6 & 105 & 2814 & 2160 & 338 & 10 & 20 & 7 & $\begin{array}{r}4962 \\
7 \\
\end{array}$ \\
\hline MA-20 & Turquoise & 196 & 191 & 1945 & 23 & 27 & 494 & 9775 & 15 & 90 & 29995 & 207 & 122 & 125 & 324 & 8 & 66 & 77 & 49 & 182 & 13 & 24 & 10 & 249 \\
\hline MA-21 & Turquoise & 53 & 238 & 1486 & 23 & 14 & 391 & 9163 & 57 & 63 & 30050 & 1045 & 93 & 32 & 238 & 5 & 31 & 384 & 12 & 98 & 8 & 14 & 6 & 240 \\
\hline MA-24 & Turquoise & 167 & 213 & 1489 & 23 & 20 & 390 & 7859 & 5 & 71 & 18081 & 191 & 36 & 97 & 260 & 6 & 37 & 228 & 10 & 124 & 8 & 16 & 7 & 162 \\
\hline MA-27 & Dark-Blue, White & 268 & 178 & 1426 & 26 & 23 & 411 & 10294 & 3466 & 268 & 1723 & 132 & 2773 & 92 & 383 & 9 & 77 & 4 & 1 & 307 & 14 & 27 & 11 & 39 \\
\hline MA-28a & Turquoise & 213 & 161 & 1049 & 19 & 22 & 309 & 6895 & 123 & 54 & 31778 & 135 & 152 & 74 & 359 & 7 & 64 & 41 & 32 & 243 & 13 & 25 & 11 & 562 \\
\hline \multicolumn{25}{|c|}{ Lahore samples } \\
\hline LF-02 & White & 32 & 225 & 559 & 11 & 3 & 333 & 5600 & 2 & 5 & 53 & 42 & 4 & 40 & 226 & 6 & 50 & 2 & 0 & 124 & 9 & 17 & 7 & 420 \\
\hline LF-03 & Dark-Blue & 40 & 233 & 595 & 12 & 8 & 451 & 17471 & 6909 & 127 & 374 & 22 & 1294 & 28 & 311 & 7 & 72 & 4 & 0 & 168 & 9 & 17 & 7 & 178 \\
\hline LF-04 & Dark-Blue & 48 & 177 & 685 & 13 & 11 & 466 & 8226 & 3186 & 51 & 362 & 34 & 553 & 68 & 271 & 7 & 55 & 9 & 6 & 164 & 10 & 19 & 8 & 757 \\
\hline LF-05 & Turquoise & 30 & 166 & 439 & 9 & 7 & 313 & 4552 & 11 & 40 & 24724 & 23 & 91 & 50 & 248 & 5 & 47 & 28 & 25 & 173 & 7 & 13 & 6 & 587 \\
\hline
\end{tabular}


Appendix A. List of samples with details of the buildings from where sourced. The MA series are from various buildings at Makli Hill, while the LF series are from Lahore Fort.

\begin{tabular}{|c|c|c|c|c|c|}
\hline No. & Sample & Type & Glaze colours & Building & Period/date* \\
\hline 1 & MA-01 & Polychrome & Dark-Blue, White, Turquoise & Tomb of Sultan Ibrahim & 1558-1559 CE \\
\hline 2 & MA-02 & Polychrome & Dark-Blue, White, Turquoise & Tomb of Sultan Ibrahim & 1558-1559 CE \\
\hline 3 & MA-03 & Monochrome & Turquoise & Tomb of Sultan Ibrahim & 1558-1559 CE \\
\hline 4 & MA-04 & Polychrome & Dark-Blue, White, Turquoise & Tomb of Sultan Ibrahim & 1558-1559 CE \\
\hline 5 & MA-05 & Monochrome & Dark-Blue & Tomb of Dewan Shurfa Khan & c. $1638 \mathrm{CE}$ \\
\hline 6 & MA-06 & Monochrome & Turquoise & Tomb of Dewan Shurfa Khan & c. $1638 \mathrm{CE}$ \\
\hline 7 & MA-07 & Monochrome & White & Tomb of Dewan Shurfa Khan & c. $1638 \mathrm{CE}$ \\
\hline 8 & MA-08 & Monochrome & Turquoise & Tomb of Dewan Shurfa Khan & c. $1638 \mathrm{CE}$ \\
\hline 9 & MA-09 & Monochrome & White & Tomb of Dewan Shurfa Khan & c. $1638 \mathrm{CE}$ \\
\hline 10 & MA-10 & Polychrome & Dark-Blue, White & Unknown Enclosure-1 & Unknown \\
\hline 11 & MA-11 & Polychrome & Dark-Blue, White, Turquoise & Unknown Enclosure-1 & Unknown \\
\hline 12 & MA-12 & Polychrome & Dark-Blue, White, Turquoise & Tomb of Mirza Jani Beg & c. $1600-1601 \mathrm{CE}$ \\
\hline 13 & MA-13 & Polychrome & Dark-Blue, White, Turquoise & Tomb of Mirza Jani Beg & c. $1600-1601 \mathrm{CE}$ \\
\hline 14 & MA-14 & Polychrome & Dark-Blue, White & Enclosure & Unknown \\
\hline 15 & MA-15 & Monochrome & Turquoise & Enclosure & Unknown \\
\hline 16 & MA-16 & Polychrome & Dark-Blue, White, Turquoise & Tomb of Khusrau Khan Charkhas & $1601-1602 \mathrm{CE}$ \\
\hline 17 & MA-17 & Polychrome & Dark-Blue, White & Unknown Platform & Unknown \\
\hline 18 & MA-18 & Monochrome & Turquoise & Enclosure of Mirza Baqi Baig Uzbek & $1641 \mathrm{CE}$ \\
\hline 19 & MA-19 & Polychrome & Dark-Blue, White, Turquoise & Sayyid Amir Khan grave enclosure & $1715 \mathrm{CE}$ \\
\hline 20 & MA-20 & Monochrome & Turquoise & Tomb of Shaikh Hammad Jamali & c. $1389-1392 \mathrm{CE}$ \\
\hline 21 & MA-21 & Monochrome & Turquoise & Unknown Tomb-1 & Unknown \\
\hline 22 & MA-22 & Monochrome & Turquoise & Unknown Tomb-2 & 17th cent. \\
\hline 23 & MA-23 & Monochrome & Turquoise & Unknown Enclosure-2 & 16th cent. \\
\hline 24 & MA-24 & Monochrome & Turquoise & Unknown Enclosure-3 & 17th cent. \\
\hline 25 & MA-25 & Monochrome & Turquoise & Unknown Enclosure-3 & 17th cent. \\
\hline 26 & MA-26 & Polychrome & Dark-Blue, White, Turquoise & Unknown Tomb Enclosure & 17 th cent. \\
\hline 27 & MA-27 & Polychrome & Dark-Blue, White & Unknown Tomb Enclosure & 17th cent. \\
\hline 28 & MA-28a & Monochrome & Turquoise & Unknown Tomb Enclosure & 17 th cent. \\
\hline 29 & $M A-28 b$ & Monochrome & Dark-Blue & Unknown Tomb Enclosure & 17th cent. \\
\hline 30 & LF-01 & Monochrome & Yellow & Lahore Fort & c. $1625-1630 \mathrm{CE}$ \\
\hline 31 & LF-02 & Monochrome & White & Lahore Fort & c. $1625-1630 \mathrm{CE}$ \\
\hline 32 & LF-03 & Monochrome & Dark-Blue & Lahore Fort & c. $1625-1630 \mathrm{CE}$ \\
\hline 33 & LF-04 & Monochrome & Dark-Blue & Lahore Fort & c. $1625-1630 \mathrm{CE}$ \\
\hline 34 & LF-05 & Monochrome & Turquoise & Lahore Fort & c. $1625-1630 \mathrm{CE}$ \\
\hline 35 & LF-06 & Monochrome & Orange & Lahore Fort & c. $1625-1630 \mathrm{CE}$ \\
\hline 36 & LF-07a & Monochrome & Green & Lahore Fort & c. $1625-1630 \mathrm{CE}$ \\
\hline 37 & LF-07b & Monochrome & Yellow & Lahore Fort & c. $1625-1630 \mathrm{CE}$ \\
\hline 38 & LF-08 & Monochrome & Green & Lahore Fort & c. $1625-1630 \mathrm{CE}$ \\
\hline
\end{tabular}

*Dates where assigned require ratification. 
Appendix B. Reduced chemical compositions of the Makli tile glazes. All results are in wt\% from SEM-EDS analyses and normalised to $100 \%$. Results below the detection limit of the instrument are provided for comparative purposes only.

\begin{tabular}{|c|c|c|c|c|c|c|c|c|c|c|}
\hline Sample & Type & Glaze colours & $\mathrm{SiO}_{2}$ & $\mathrm{Na}_{2} \mathrm{O}$ & $\mathrm{CaO}$ & $\mathrm{K}_{2} \mathrm{O}$ & MgO & $\mathrm{Al}_{2} \mathrm{O}_{3}$ & $\mathrm{FeO}$ & $\mathrm{TiO}_{2}$ \\
\hline MA-01 & Polychrome & Dark-Blue, White, Turquoise & 67.9 & 15.3 & 5.9 & 3.2 & 3.3 & 2.6 & 1.7 & 0.3 \\
\hline MA-02 & Polychrome & Dark-Blue, White, Turquoise & 69.3 & 13.0 & 7.1 & 3.6 & 3.7 & 2.0 & 1.0 & 0.2 \\
\hline MA-03 & Monochrome & Turquoise & 71.8 & 10.8 & 5.9 & 4.0 & 3.3 & 2.8 & 1.2 & 0.2 \\
\hline MA-04 & Polychrome & Dark-Blue, White, Turquoise & 69.2 & 14.7 & 5.6 & 2.8 & 3.2 & 2.5 & 1.6 & 0.3 \\
\hline MA-05 & Monochrome & Dark-Blue & 67.0 & 14.7 & 6.7 & 2.9 & 3.9 & 2.8 & 1.7 & 0.3 \\
\hline MA-06 & Monochrome & Turquoise & 68.2 & 13.9 & 6.5 & 3.3 & 3.9 & 2.8 & 1.1 & 0.3 \\
\hline MA-07 & Monochrome & White & 66.7 & 14.8 & 6.9 & 3.0 & 4.1 & 3.0 & 1.3 & 0.2 \\
\hline MA-08 & Monochrome & Turquoise & 72.6 & 12.0 & 5.1 & 3.1 & 3.2 & 2.6 & 1.1 & 0.2 \\
\hline MA-09 & Monochrome & White & 67.3 & 13.6 & 7.4 & 3.0 & 4.4 & 2.8 & 1.2 & 0.3 \\
\hline MA-10 & Polychrome & Dark-Blue, White & 68.3 & 12.0 & 6.3 & 4.0 & 3.8 & 3.4 & 1.9 & 0.3 \\
\hline MA-11 & Polychrome & Dark-Blue, White, Turquoise & 71.3 & 10.9 & 6.0 & 3.8 & 3.6 & 2.5 & 1.6 & 0.3 \\
\hline MA-12 & Polychrome & Dark-Blue, White, Turquoise & 76.2 & 15.6 & 1.4 & 3.4 & 0.3 & 2.1 & 0.7 & 0.2 \\
\hline MA-13 & Polychrome & Dark-Blue, White, Turquoise & 76.3 & 13.1 & 2.2 & 4.2 & 0.5 & 2.6 & 0.9 & 0.2 \\
\hline MA-14 & Polychrome & Dark-Blue, White & 73.4 & 6.3 & 4.0 & 5.3 & 2.4 & 6.1 & 2.0 & 0.5 \\
\hline MA-15 & Monochrome & Turquoise & 71.5 & 10.1 & 6.2 & 3.9 & 4.0 & 2.8 & 1.2 & 0.3 \\
\hline MA-16 & Polychrome & Dark-Blue, White, Turquoise & 72.1 & 9.7 & 6.5 & 4.2 & 3.9 & 2.3 & 1.2 & 0.3 \\
\hline MA-17 & Polychrome & Dark-Blue, White & 70.0 & 11.9 & 6.7 & 3.5 & 3.9 & 2.5 & 1.2 & 0.3 \\
\hline MA-18 & Monochrome & Turquoise & 75.3 & 12.0 & 4.4 & 3.8 & 0.7 & 2.3 & 1.2 & 0.2 \\
\hline MA-19 & Polychrome & Dark-Blue, White, Turquoise & 72.8 & 10.1 & 5.7 & 4.2 & 3.6 & 2.4 & 1.0 & 0.3 \\
\hline MA-20 & Monochrome & Turquoise & 69.6 & 11.3 & 6.1 & 4.5 & 3.7 & 3.2 & 1.2 & 0.3 \\
\hline MA-21 & Monochrome & Turquoise & 64.6 & 21.5 & 4.3 & 2.4 & 3.1 & 2.6 & 1.2 & 0.3 \\
\hline MA-22 & Monochrome & Turquoise & 72.0 & 10.7 & 5.7 & 4.0 & 2.8 & 3.1 & 1.4 & 0.3 \\
\hline MA-23 & Monochrome & Turquoise & 71.6 & 9.1 & 5.4 & 6.0 & 3.6 & 2.7 & 1.1 & 0.3 \\
\hline MA-24 & Monochrome & Turquoise & 69.7 & 12.8 & 6.2 & 3.1 & 3.9 & 2.8 & 1.1 & 0.3 \\
\hline MA-25 & Monochrome & Turquoise & 66.8 & 14.2 & 7.3 & 2.5 & 3.9 & 3.4 & 1.7 & 0.3 \\
\hline MA-26 & Polychrome & Dark-Blue, White, Turquoise & 72.5 & 11.1 & 5.6 & 3.6 & 3.8 & 2.3 & 0.9 & 0.2 \\
\hline MA-27 & Polychrome & Dark-Blue, White & 71.4 & 9.9 & 6.5 & 3.5 & 4.4 & 2.9 & 1.2 & 0.3 \\
\hline MA-28a & Monochrome & Turquoise & 72.5 & 10.8 & 6.2 & 3.6 & 3.8 & 2.0 & 0.9 & 0.2 \\
\hline MA-28b & Monochrome & Dark-Blue & 70.1 & 10.4 & 6.6 & 3.9 & 3.9 & 3.0 & 1.7 & 0.3 \\
\hline
\end{tabular}


Appendix C. Reduced chemical compositions of the Lahore tile glazes. All results are in wt\% from SEM-EDS analyses and normalised to $100 \%$.

\begin{tabular}{|c|c|c|c|c|c|c|c|c|c|}
\hline Sample & Type & Glaze colour & $\mathrm{SiO}_{2}$ & $\mathrm{Na}_{2} \mathrm{O}$ & $\mathrm{CaO}$ & $\mathrm{K}_{2} \mathrm{O}$ & MgO & $\mathrm{Al}_{2} \mathrm{O}_{3}$ & $\mathrm{FeO}$ \\
\hline LF-01 & Monochrome & Yellow & 68.6 & 15.2 & 3.5 & 7.4 & 2.7 & 1.9 & 0.8 \\
\hline LF-02 & Monochrome & White & 66.1 & 19.6 & 3.7 & 3.4 & 3.3 & 2.7 & 1.1 \\
\hline LF-03 & Monochrome & Dark-Blue & 67.1 & 17.8 & 5.1 & 2.8 & 3.0 & 2.3 & 1.9 \\
\hline LF-04 & Monochrome & Dark-Blue & 67.0 & 16.9 & 4.8 & 3.4 & 3.1 & 3.5 & 1.2 \\
\hline LF-05 & Monochrome & Turquoise & 68.9 & 16.9 & 5.7 & 2.5 & 3.2 & 2.1 & 0.7 \\
\hline LF-06 & Monochrome & Orange & 69.6 & 16.6 & 4.3 & 3.4 & 3.1 & 2.1 & 0.8 \\
\hline LF-07a & Monochrome & Green & 68.1 & 17.3 & 4.1 & 4.0 & 3.1 & 2.4 & 1.1 \\
\hline LF-07b & Monochrome & Yellow & 64.2 & 22.0 & 4.7 & 2.9 & 3.2 & 2.1 & 0.8 \\
\hline LF-08 & Monochrome & Green & 65.6 & 19.0 & 5.3 & 3.0 & 3.5 & 2.6 & 1.0 \\
\hline
\end{tabular}


Appendix D. Reduced chemical compositions of select Makli and Lahore tile glazes. All results are in wt\% from LA-ICP-MS analyses, and normalised to $100 \%$. Results have been rounded off to one decimal place for comparison with SEM-EDS analyses.

\begin{tabular}{|c|c|c|c|c|c|c|c|c|c|c|}
\hline Sample & Type & Glaze colours & $\mathrm{SiO}_{2}$ & $\mathrm{Na}_{2} \mathrm{O}$ & $\mathrm{CaO}$ & $\mathrm{K}_{2} \mathrm{O}$ & MgO & $\mathrm{Al}_{2} \mathrm{O}_{3}$ & $\mathrm{FeO}$ & $\mathrm{TiO}_{2}$ \\
\hline \multicolumn{11}{|c|}{ Makli samples } \\
\hline MA-01 & Polychrome & Dark-Blue, White, Turquoise & 68.5 & 15.8 & 5.9 & 2.9 & 3.2 & 2.5 & 1.1 & 0.2 \\
\hline MA-02 & Polychrome & Dark-Blue, White, Turquoise & 69.0 & 13.1 & 7.1 & 3.5 & 3.6 & 2.5 & 1.0 & 0.2 \\
\hline MA-04 & Polychrome & Dark-Blue, White, Turquoise & 70.9 & 14.0 & 5.8 & 2.4 & 2.6 & 2.7 & 1.4 & 0.2 \\
\hline MA-05 & Monochrome & Dark-Blue & 67.5 & 14.0 & 6.9 & 3.1 & 3.6 & 3.3 & 1.5 & 0.2 \\
\hline MA-08 & Monochrome & Turquoise & 72.3 & 12.3 & 4.9 & 2.9 & 3.1 & 3.1 & 1.1 & 0.2 \\
\hline MA-09 & Monochrome & White & 68.7 & 13.7 & 6.3 & 2.9 & 3.8 & 3.2 & 1.1 & 0.2 \\
\hline MA-12 & Polychrome & Dark-Blue, White, Turquoise & 77.4 & 14.8 & 1.5 & 3.2 & 0.3 & 2.0 & 0.6 & 0.2 \\
\hline MA-13 & Polychrome & Dark-Blue, White, Turquoise & 75.7 & 12.7 & 3.2 & 4.0 & 0.6 & 2.8 & 0.9 & 0.2 \\
\hline MA-16 & Polychrome & Dark-Blue, White, Turquoise & 72.3 & 9.8 & 6.2 & 3.9 & 3.9 & 2.6 & 1.1 & 0.2 \\
\hline MA-18 & Monochrome & Turquoise & 76.0 & 11.7 & 4.6 & 3.6 & 0.8 & 2.4 & 0.6 & 0.2 \\
\hline MA-20 & Monochrome & Turquoise & 68.3 & 11.7 & 6.7 & 4.1 & 4.0 & 3.5 & 1.3 & 0.3 \\
\hline MA-21 & Monochrome & Turquoise & 64.6 & 21.9 & 4.5 & 2.2 & 2.9 & 2.5 & 1.3 & 0.3 \\
\hline MA-24 & Monochrome & Turquoise & 71.0 & 12.6 & 5.7 & 2.9 & 3.6 & 2.8 & 1.0 & 0.3 \\
\hline MA-27 & Polychrome & Dark-Blue, White & 71.4 & 9.9 & 6.6 & 3.3 & 4.3 & 2.9 & 1.3 & 0.2 \\
\hline MA-28a & Monochrome & Turquoise & 72.7 & 10.7 & 6.1 & 3.5 & 3.7 & 2.3 & 0.9 & 0.2 \\
\hline \multicolumn{11}{|c|}{ Lahore samples } \\
\hline LF-02 & Monochrome & White & 64.7 & 20.1 & 5.7 & 3.0 & 3.1 & 2.6 & 0.7 & 0.1 \\
\hline LF-03 & Monochrome & Dark-Blue & 64.1 & 19.0 & 5.8 & 2.5 & 3.2 & 3.0 & 2.3 & 0.1 \\
\hline LF-04 & Monochrome & Dark-Blue & 68.3 & 15.3 & 5.4 & 3.1 & 2.8 & 3.9 & 1.1 & 0.1 \\
\hline LF-05 & Monochrome & Turquoise & 70.3 & 15.9 & 4.9 & 2.5 & 2.7 & 3.0 & 0.6 & 0.1 \\
\hline
\end{tabular}




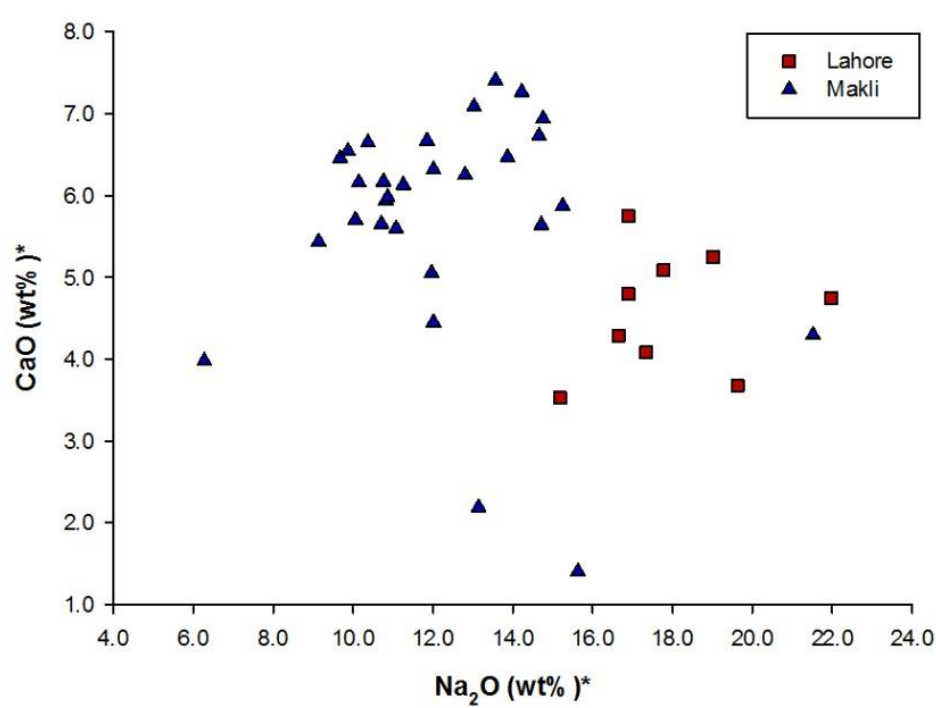

Appendix E. Scatter plot of soda versus lime contents of the Makli and Lahore glazes. ${ }^{*}$ indicates reduced composition.

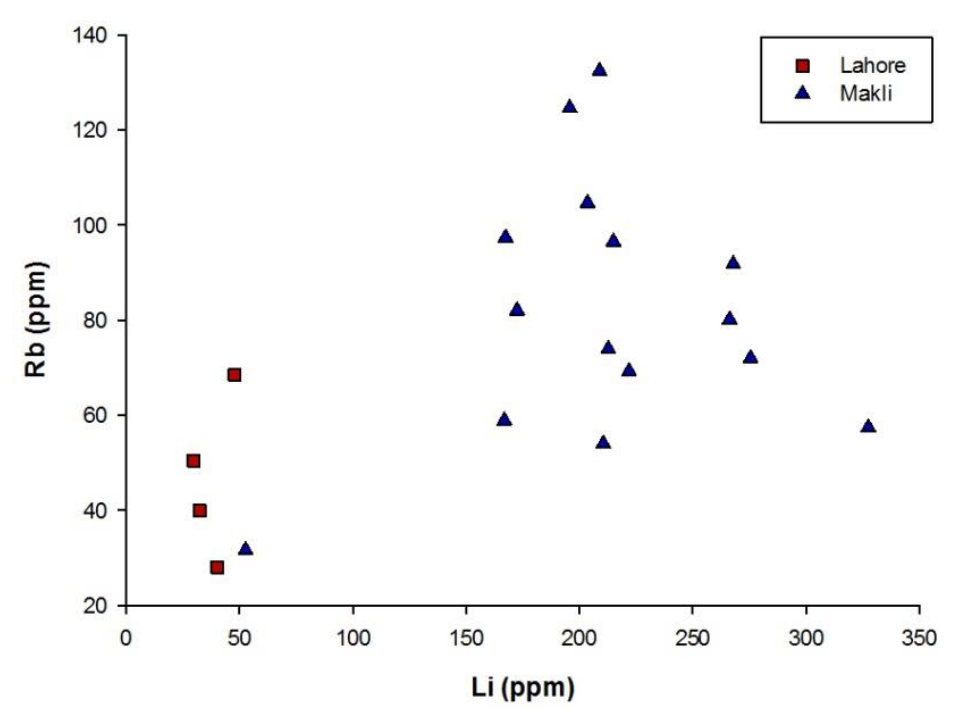

Appendix F. Scatter plot of lithium versus rubidium contents of select Makli and Lahore glazes. MA-21 is an exception to the Makli grouping, lying closer instead to the Lahore group. 